\title{
Progress on High-Speed 980 nm VCSELs for Short-Reach Optical Interconnects
}

\author{
Alex Mutig and Dieter Bimberg \\ Institut für Festkörperphysik and Zentrum für Nanophotonik, Technische Universität Berlin, Hardenbergstraße 36, \\ 10623 Berlin, Germany \\ Correspondence should be addressed to Alex Mutig, alex.mutig@berkeley.edu
}

Received 29 March 2011; Accepted 8 June 2011

Academic Editor: Krassimir Panajotov

Copyright ( 92011 A. Mutig and D. Bimberg. This is an open access article distributed under the Creative Commons Attribution License, which permits unrestricted use, distribution, and reproduction in any medium, provided the original work is properly cited.

Progress of high-speed vertical cavity surface emitting lasers (VCSEL) operating around $980 \mathrm{~nm}$ is reviewed. A special focus is on their applications for future short-reach optical interconnects, for example, in high-performance computers (HPC). The wavelength of $980 \mathrm{~nm}$ has fundamental advantages for these applications and plays a significant role in VCSEL research today. The present data rates of $980 \mathrm{~nm}$ VCSELs exceed $40 \mathrm{Gbit} / \mathrm{s}$, and excellent temperature stability has been reported. The major concepts leading to these impressive developments are presented.

\section{Introduction}

The perpetually increasing demand of our modern society for ever faster access to ever larger amounts of information requires a corresponding permanent increase of the computational power of data centres and high-performance computers (HPC) for rapid and efficient data processing and routing. The motor of the progress in HPC performance is the downscaling of Si-based integrated circuit (IC) technology, as predicted by Moore's Law. While currently the fabrication process of complementary metaloxide-semiconductor (CMOS) ICs is based on the $32 \mathrm{~nm}$ technology node, future generations of CMOS chips based on $22,15,11$, and $8 \mathrm{~nm}$ technology nodes are expected to appear just within a decade from now [1]. The ever increasing computational power of central processing units (CPU) and storage capability of memory elements logically and unavoidable requires a corresponding strong increase of the performance of data transmission lines connecting chips with each other. Traditional copper-based interconnects quickly run into their physical limitations as signal frequencies approach $10 \mathrm{GHz}$, which are among other high losses, large signal attenuation, large power dissipation, signal distortion, electromagnetic interference (EMI), and crosstalk [2-6]. The ultimate solution is brought by optical interconnects [7-11], which are consistently replacing wirebased electrical links for rack-to-rack, box-to-box, and board-to-board communication and penetrating to even shorter transmission distances. It is expected that just within a decade from now optical links will reach module and chip levels [7].

The success of the optical technologies in the HPC applications originates from the decisive advantages of vertical cavity surface emitting lasers (VCSEL) [12-15] as a highquality laser light source for short-reach optical interconnects with a large number of channels. The most important and beneficial VCSEL properties are: low-threshold and operating currents; high-efficiency and low-power consumption; a near-circular output beam enabling easy coupling into optical fibers, high-temperature stability, high reliability and easy packaging, straightforward fabrication of dense arrays, and planar fabrication technology with on-wafer characterization, enabling inexpensive production and testing of thousands of devices on a single wafer, resulting in a price of only several cents per laser. The availability of VCSELs enabled penetration of optical links first to the local area network (LAN) level and afterwards down to the intra-rack level in modern HPC applications [16, 17]. Today tens of thousands of optical interconnects based on oxide-confined 
VCSELs $[18,19]$ and multimode fibers are routinely installed practically into each HPC system [20, 21].

Driven by the market demand for more bandwidth, many academic institutions and industrial companies focused their research on high-speed VCSELs, resulting in the demonstration of devices capable of error-free data transmission at bit rates of up to $40 \mathrm{Gbit} / \mathrm{s}$ at room temperature at the commercially important wavelength of $850 \mathrm{~nm}$ [22-40], which is the standard wavelength for LAN applications. However, as optical links penetrate to even shorter distances down to the board, module, and chip levels and the number of channels drastically increases, additional crucial requirements for laser light sources arise. Since temperatures inside computer racks can be as high as $85^{\circ} \mathrm{C}$ and even larger, high temperature stability of VCSELs becomes very important. Ability to operate in a wide temperature range, preferably without adjustment of the operating parameters to the temperature changes in order to reduce costs for the driver electronics, is vital for module-to-module and chipto-chip optical interconnects. Additionally, the limited space and power budget in HPC systems requires fabrication of VCSELs with very high packaging densities and low power consumption. Already now up to one million VCSELs are encapsulated just in one supercomputer, and in the future Petaflop and Exaflop systems the number of optical links will reach hundreds of millions per machine [21]. Consequently, high bit rate, high-temperature stability, high packaging density and low power consumption are the major ultimate requirements for laser light sources of future optical links in HPC applications.

Appearance of these new challenges motivated the research and development of high-speed GaAs-based VCSELs emitting at longer wavelengths, as compared to the standard wavelength of $850 \mathrm{~nm}$. In particular, devices operating between $980 \mathrm{~nm}$ and $1300 \mathrm{~nm}$ have been investigated with great success by different universities and industrial companies [41-82], whereby most impressive high-speed results were achieved in the wavelength range from 980 to $1100 \mathrm{~nm}$ [41-71]. Longer wavelengths provide decisive advantages to fulfil the described requirements for future short-reach optical interconnects in HPC systems as compared to $850 \mathrm{~nm}$. The main advantage is the transparency of the GaAs material at, for example, 980 or $1100 \mathrm{~nm}$. A transparent substrate facilitates a straightforward fabrication of bottomemitting lasers, drastically increasing the packaging density. Incorporation of binary GaAs layers into distributed Bragg reflectors (DBR) significantly increases both thermal and electrical conductivity of the device, leading to lower internal temperatures and increasing high temperature stability. The increased potential modulation depth of the quantum wells (QW) additionally increases the temperature stability of the VCSELs, and the smaller bandgap of the active layers results in lower threshold and operating voltages, leading to lower power consumption. The higher In-content in the InGaAs QWs emitting at, for example, $980 \mathrm{~nm}$ leads to a larger compressive strain as compared to QWs emitting at $850 \mathrm{~nm}$ for a given QW thickness, increasing differential gain, the relaxation resonance frequency, and ultimately the VCSEL's bandwidth [83].
Analyzing all the described advantages, it appears logically that longer wavelengths, for example, 980 or $1100 \mathrm{~nm}$, are the natural choice for GaAs-based VCSELs targeting future high-speed high-density applications in HPCs. They naturally provide higher speed, higher temperature stability, higher packaging density, and lower power consumption as compared to the standard wavelength of $850 \mathrm{~nm}$. Indeed the first VCSELs operating at the bit rate of $40 \mathrm{Gbit} / \mathrm{s}$ at room temperature and at $25 \mathrm{Gbit} / \mathrm{s}$ at elevated temperatures were demonstrated at the wavelength of $1100 \mathrm{~nm}$ [41-44]. However, the wavelength of $980 \mathrm{~nm}$ has several physical advantages as compared to $1100 \mathrm{~nm}$, among other lower free carrier absorption and more relaxed constraints regarding the growth of highly strained QWs, since the critical thickness of these layers is larger for the wavelength of $980 \mathrm{~nm}$ and major positive effects of the compressive strain are expected to appear already at moderate In compositions [38]. The wavelength of $980 \mathrm{~nm}$ is also preferable for optical links based on polymer waveguides, since their absorption and dispersion coefficients are wavelength dependent [7]. Because of these advantages, the fastest VCSELs at the moment both at room and elevated temperatures operate at $980 \mathrm{~nm}$ at bit rates as high as $44 \mathrm{Gbit} / \mathrm{s}$ at $25^{\circ} \mathrm{C}$ and $38 \mathrm{Gbit} / \mathrm{s}$ at $85^{\circ} \mathrm{C}[62,63]$.

Considering the importance of the market demand for high-quality laser light sources for future high-speed highdensity optical interconnects in HPC applications, as well as in view of record results with VCSELs emitting at $980 \mathrm{~nm}$, we will review here the progress achieved over the last years in this field. Hereby we will mostly concentrate on the development of high-speed $980 \mathrm{~nm}$ VCSELs operating in a wide temperature range from room temperature up to elevated temperatures of $85^{\circ} \mathrm{C}$ and larger.

\section{Laser Bandwidh and High-Temperature Stability}

Semiconductor laser dynamics is commonly described in terms of the rate equation theory $[83,84]$, which is a relatively uncomplicated and at the same time powerful approach enabling both qualitative and quantitative analysis of high-speed laser properties. The laser performance for high-speed data transmission is determined by its small signal modulation response, which can be divided into two parts. The first part describes intrinsic properties of the laser structure and is given by the following equation:

$$
H(f)=\frac{f_{R}^{2}}{f_{R}^{2}-f^{2}+j \cdot f \cdot(\gamma / 2 \pi)},
$$

where $f_{R}$ represents the relaxation resonance frequency, $\gamma$ stays for the damping factor, $f$ is the frequency, and $j$ is imaginary unit. Multiplied by the corresponding lowpass response, which represents electrical parasitic elements inside of the device, for example, parasitic resistances and capacitances associated with different parts of the laser structure like electrical contacts, oxide aperture and so forth, it gives the complete small signal modulation response of the semiconductor laser. Electrical parasitics are characterized by 
the form of the low-pass function as well as by the electrical parasitics cut-off frequency $f_{P}$, at which the high-frequency electrical signal reaching the laser-active region decreases by $3 \mathrm{~dB}$. It has been theoretically and experimentally demonstrated that the index-guided multimode VCSELs with highly overlapped transverse fields (e.g., oxide-confined VCSELs) exhibit a single relaxation resonance frequency $[85,86]$ similar to the single-mode devices, thus the single-mode rate equation theory presented here can be applied.

To achieve high bandwidth, a VCSEL should rapidly reach large relaxation resonance frequency, which increases with injected current, as determined by the following equation:

$$
f_{R}=D \cdot \sqrt{I-I_{\mathrm{th}}},
$$

where $D$ is the so-called $D$-factor, $I$ is the driving current, and $I_{\text {th }}$ is the threshold current of the VCSEL. Therefore, it is important to realize structures with a high $D$-factor, which is determined by the physical and geometrical properties of the active region and of the cavity

$$
D=\sqrt{\frac{v_{g} \cdot(\partial g / \partial N)}{4 \pi^{2} \cdot q \cdot V_{P}} \eta_{i},}
$$

where $v_{g}$ is the group velocity of light, $\partial g / \partial N$ is the differential gain, $q$ is the elementary charge, $V_{P}$ is the effective mode volume, and $\eta_{i}$ is the current injection efficiency, which is the fraction of the terminal current that generates carriers in the active region.

In addition to high relaxation resonance frequencies, also low damping factors $\gamma$ are decisive to achieve high bandwidth. The damping factor increases with increase of the relaxation resonance frequency, as described by the following equation:

$$
\gamma=K \cdot f_{R}^{2}+\gamma_{0},
$$

where $K$ is the so-called $K$-factor and $\gamma_{0}$ is the damping factor offset, whereby the damping factor offset $\gamma_{0}$ normally plays a role only at small currents near the threshold. Thus to decrease the damping, it is very important to have a small $K$-factor, which is again determined by the physical and geometrical properties of the active region and cavity

$$
K=4 \pi^{2} \tau_{p}\left(1+\frac{\Gamma \cdot\left(-\partial g / \partial N_{P}\right)}{\partial g / \partial N}\right)
$$

where $\tau_{p}$ is the photon lifetime inside the cavity, $\Gamma$ is the optical confinement factor, and $\partial g / \partial N_{P}$ is a derivative of the gain with respect to the photon density, which depends on the empirical gain compression factor $\varepsilon$.

The small signal modulation response and thus the highspeed physical properties of a VCSEL are determined by three parameters: the relaxation resonance frequency $f_{R}$, the damping factor $\gamma$, and the parasitic cut-off frequency $f_{P}$. Accordingly, there are three physical limitations controlling high-speed performance of a semiconductor laser: thermal, damping, and parasitic limits.
The thermal limitation arises from the fact that according to (2) the relaxation resonance frequency increases with current, but because of internal heating at high injection levels, it saturates at some maximum value $f_{R, \max }$ correspondingly leading to a saturation of the bandwidth $f_{3 \mathrm{~dB}}$. Thus in the absence of negative effects of the damping and electrical parasitic, the maximum achievable bandwidth $f_{3 \mathrm{~dB} \text {,thermal }}$ is given by:

$$
f_{3 \mathrm{~dB}, \text { thermal }}=\sqrt{1+\sqrt{2}} f_{R, \text { max }} .
$$

Limitation by electrical parasitics comes mainly from the parasitic resistances and capacitances inside of the device. If a VCSEL would be limited only by electrical parasitic elements, its maximal achievable bandwidth $f_{3} \mathrm{~dB}$,parasitics would be

$$
f_{3 \mathrm{~dB}, \text { parasitics }}=(2+\sqrt{3}) f_{P} .
$$

Finally, the maximum achievable bandwidth in the case of the limitation only by the damping $f_{3} \mathrm{~dB}$,damping would be determined by the $K$-factor:

$$
f_{3 \mathrm{~dB}, \mathrm{damping}}=\frac{2 \sqrt{2} \pi}{K} .
$$

In a common case, the bandwidth of a VCSEL is limited not only by one type of limitations but by two or even all the three limits: thermal effects, damping and electrical parasitics. The main task for achieving high speed is, therefore, a carefully optimization of different laser parameters, both in the epitaxial structure as well as in the device design, and an effective combination of many improvement concepts as well as identification of proper compromises between different competing processes. In addition, for future market applications, applied concepts are restricted to those, which would not have a significant negative impact onto the laser reliability and costs.

Equations (1)-(8) from the rate equation theory can be applied to analyze physical limitations of the fabricated devices and to identify and develop concepts for improving high-speed laser performance. Therefore, small signal modulation curves of the lasers are measured at different current levels and temperatures in a relatively straightforward experiment using calibrated network analyzer and photodetector. Thereafter, the theoretical function (1), multiplied by the appropriate low-pass curve of the electrical parasitics, can be fitted to experimental results, giving the relaxation resonance frequency $f_{R}$, the damping factor $\gamma$, and the parasitic cutoff frequency $f_{P}$ for every measured small signal modulation response curve. However, to complete the fitting procedure, an assumption about the form of the low pass of electrical parasitics should be made. Therefore, a more accurate and precise way to extract the laser parameters is additionally to measure the electrical scattering parameters $S_{11}$ in the same experiment and to extract the low-pass curve of electrical parasitics by fitting parameters of the equivalent circuit of the laser to the measurement results. The appropriate equivalent circuit of a VCSEL commonly reflects the basic parasitic resistances and capacitances in the device, including 
resistances of the active region $R_{a}$ and of the top and of the bottom DBR mirrors $R_{\mathrm{mt}}$ and $R_{\mathrm{mb}}$, respectively, as well as the active region capacitance $\mathrm{C}_{j}$, the capacitance of the oxide aperture and the underlying intrinsic region $C_{o}$, and the parasitic capacitance of the contact pads $C_{p}$, as demonstrated in Figure 1(a), where a typical structure of oxide-confined VCSELs together with the electrical parasitic elements is shown.

The equivalent circuit shown in Figure 1(a) can be simplified using common rules. Since the two capacitances $C_{o}$ and $C_{j}$ are connected in parallel, they can be combined to one capacitance $C_{a}$. Also both mirror resistances $R_{\mathrm{mt}}$ and $R_{\mathrm{mb}}$ together with eventually considerable contact resistances (not shown in the figure) can be represented by one common resistance $R_{m}$. These simplifications lead to the equivalent circuit demonstrated in Figure 1(b), which now has only four fitting parameters: both resistances and capacitances. For the case of, for example, wire bonding, also parasitic inductances could be included into the model. $Z_{0}$ represents hereby the driver impedance and is usually $50 \mathrm{Ohm}$. Equivalent circuits identical or similar to the model demonstrated in the Figure 1(b) are commonly used to extract values of electrical parasitic element in VCSELs at different wavelengths, for example, $850 \mathrm{~nm}[24,37], 980 \mathrm{~nm}[47,53]$, and $1100 \mathrm{~nm}$ [41], leading to accurate analysis of the high-speed laser performance and its limiting factors.

By fitting the parameters of the laser equivalent circuit to the measured $S_{11}$ curves, the low-pass curve of electrical parasitics can be calculated and used for the fitting of the small signal modulation response of the VCSELs together with (1). Following this procedure, limiting factors of the high-speed laser performance can be identified and physical processes in the VCSEL as well as their interactions can be properly understood.

Although the development of high-speed VCSELs operating at a defined ambient temperature is a very complicated and nontrivial task, realization of VCSELs capable of highspeed data transmission in a wide temperature range adds a new dimension of the complexity to the high-bandwidth problem. It arises from the fact that practically all physical quantities are more or less temperature dependent. This could be expressed by adding temperature dependence to all parameters in the basic equations (1)-(5). While some physical quantities, for example, effective mode volume $V_{P}$ or optical confinement factor $\Gamma$, are less temperature sensitive, the majority of the important device parameters, for example, threshold current $I_{\text {th }}$, differential gain $\partial g / \partial N$, relaxation resonance frequency $f_{R}$, and many other are strongly temperature dependent, greatly increasing the complexity of the problem of maintaining a proper high-speed performance over a wide temperature range.

To achieve stable performance in a wide ambient temperature range, both the temperature dependence of the physical parameters, for example, differential gain, threshold current, damping, and so forth, as well as the temperature increase inside the device should be minimized. The complexity of the first task is the limited set of available semiconductor materials with defined physical properties and their dependence on temperature. Nevertheless, by applying novel concepts, for

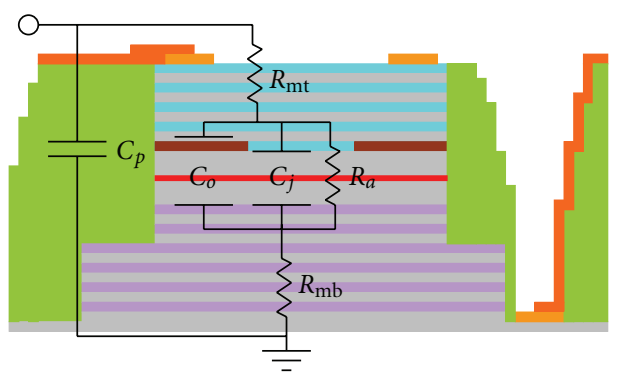

(a)

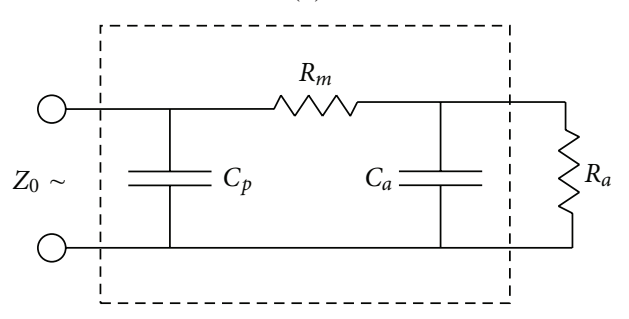

(b)

FIGURE 1: Electrical parasitic capacitances and resistances in VCSEL (a) and the corresponding equivalent circuit with two parallel capacitances $C_{o}$ and $C_{j}$ combined together to $C_{a}$ and resistances of the both mirrors $R_{\mathrm{mt}}$ and $R_{\mathrm{mb}}$ joined to $R_{m}$ (b).

example, for the growth of the active region, for example, submonolayer (SML) growth [50-53], temperature stability of the VCSELs can be significantly increased. Additionally, VCSELs have a very elegant and effective natural mechanism to increase the high temperature stability, which is the variable detuning between the wavelength of the laser cavity resonance and the gain peak wavelength, whereby both wavelengths are defined by the laser design. Because the gain peak wavelength shifts faster with the temperature than the cavity resonance wavelength, the decrease of the gain and of the differential gain as well as the increase of internal cavity losses at higher temperatures can be compensated or even overcompensated by applying a proper detuning.

The second task, which is the reduction of the temperature variations inside of the VCSEL, can be divided into two aspects, since internal device temperature changes are caused by two phenomena: internal heating and ambient temperature changes. The problem of the internal heating is generally solved by the reduction of the heat generated inside the device at different heat sources, for example, electrical resistances, optical absorbing layers, and so forth, and by the increase of the thermal conductivity of the laser, for example, by replacing ternary materials with binary alloys, which have a much better thermal conductivity, helping to dissipate the internally generated heat. Since the changes of the ambient temperature are defined by the application, the problem of the external temperature changes has no solutions on the device development level in this sense, so that the ambient operation temperature range should be considered as a given specification, which should be fulfilled.

In spite of the above-described constraints and the complexity of the task to achieve high-speed VCSEL operation 
in a wide temperature range, impressive results have been achieved in this field with GaAs-based VCSELs emitting at different wavelengths. Following the motivation in the introduction, in the next sections we will review the progress of the VCSELs operating near the wavelength of $980 \mathrm{~nm}$ at bit rates from $20 \mathrm{Gbit} / \mathrm{s}$ up to $40 \mathrm{Gbit} / \mathrm{s}$ and even beyond.

\section{High-Speed Operation up to $25 \mathrm{~Gb} / \mathrm{s}$ at Elevated Temperatures}

In the middle 2000s, IBM started the program "Terabus" [56], which targeted development of short-reach onboard optical interconnects for future HPC applications in collaboration with Agilent, which participated also in the program "MAUI: Multiwavelength Assemblies for Ubiquitous Interconnects" [55] with similar goals. In both programs, VCSELs emitting at longer wavelengths, in particular, near the wavelength of $980 \mathrm{~nm}$, served as laser light sources because of their advantages described in the previous sections. The activity of such large companies in the field of high-speed 980-nm VCSELs promptly attracted many researchers worldwide to join this topic, which resulted in rapid progress of the VCSEL bandwidth and temperature stability.

Already in 2006, a fully functional optical link with a $4 \times 12$ VCSEL array using lasers emitting at $985 \mathrm{~nm}$ has been demonstrated by the Agilent and IBM researchers $[49,56]$. Each of the 48 VCSELs transmitted data at operation current density lower than $10 \mathrm{kA} / \mathrm{cm}^{2}$ at a bit rate of $20 \mathrm{Gbit} / \mathrm{s}$, resulting in an aggregated data bit rate of $960 \mathrm{Gbit} / \mathrm{s}$ for the whole chip. Open eyes at bit rates of up to $25 \mathrm{Gbit} / \mathrm{s}$ at elevated temperatures of up to $70^{\circ} \mathrm{C}$ have been demonstrated, which would give an aggregated data rate of 1.2 Tbit/s for the $4 \times 12 \mathrm{VCSEL}$ array, fully confirming the right choice of the program's name "Terabus".

In 2007, our group developed $980 \mathrm{~nm}$ VCSELs with active region grown in the SML growth mode [50, 51], further increasing the high temperature stability of the fabricated devices. These VCSELs have demonstrated errorfree data transmission at a bit rate of $20 \mathrm{Gbit} / \mathrm{s}$ in a wide temperature range from 25 up to $85^{\circ} \mathrm{C}$ under constant driving conditions [50], for example, operation current and modulation voltage. The latter is very important for reducing the costs, the footprint and the power consumption of the driver electronics, since no active adjustment of the driving parameters is needed to compensate for changes in ambient temperature.

In 2008 we continued the development of high-speed high-temperature-stable $980 \mathrm{~nm}$ VCSELs based on the active region grown in the SML growth mode, since this type of active region has demonstrated its high-temperature stability in the first generation of our $980 \mathrm{~nm}$ VCSELs [50, 51] described above. Similarly to the first generation, the second generation of the $980 \mathrm{~nm}$ VCSELs developed in our group [52-54] has been grown by molecular beam epitaxy (MBE) on $\mathrm{n}+\mathrm{GaAs}$ (100) substrates and utilized a triple stack of highly strained SML grown InGaAs layers. The stack was placed into the middle of the low-index $\mathrm{Al}_{0.80} \mathrm{Ga}_{0.20} \mathrm{As}$ cavity, since the $\mathrm{Al}$ content of $80 \%$ provides a better thermal conductivity and reduces the mesa capacitance due to the smaller dielectric constant as compared to for example, $\sim 30 \% \mathrm{Al}$ used conventionally. To facilitate optical and electrical confinement, aperture layers consisted of a $12 \mathrm{~nm}$ thick binary AlAs surrounded by two $9.2 \mathrm{~nm}$ thick $\mathrm{Al}_{0.90} \mathrm{Ga}_{0.10}$ As layers were utilized. During the selective wet oxidation, all three layers, including a part of the surrounding $\mathrm{Al}_{0.80} \mathrm{Ga}_{0.20}$ As material, oxidized with different oxidation rates, leading to formation of a tapered $\mathrm{Al}_{x} \mathrm{O}_{y}$ aperture, reducing optical scattering losses. The cavity length was $3 / 2$ $\lambda$. In order to improve the temperature stability of the lasers, the cavity was red shifted from the peak gain at $25^{\circ} \mathrm{C}$ by $\sim 20 \mathrm{~nm}$. To simplify device fabrication and avoid critical etching steps, optimized doped $\mathrm{Al}_{0.90} \mathrm{Ga}_{0.10} \mathrm{As} / \mathrm{GaAs}$ DBR mirrors were applied for both top and bottom mirrors. The top p-doped DBR contained 20.5 mirror pairs, while the bottom n-doped DBR consisted of 32.5 mirror pairs. To improve electrical conductivity, linear gradings with $10 \mathrm{~nm}$ thickness were utilized in the mirrors.

In addition to the appropriate epitaxial design, it is indispensable to develop a corresponding device design and device fabrication process, which will allow utilization of the internal high-speed properties of the VCSEL epitaxial material and in an ideal case without any external limitations. As described in the previous sections, important limitations of the laser speed arise from thermal heating, damping, and electrical parasitics. The electrical parasitic elements, for example, as well as most of the other limiting factors, are defined by the interplay of the internal properties of the epitaxial structure, for example, doping profiles and layer thicknesses, and of the fabrication process, for example, mesa and aperture diameters, contact dimensions, and so forth. Therefore, it is decisive to develop a fabrication flow which perfectly matches the epitaxial structure and results in the overall low electrical parasitics, low thermal heating, and low damping. While some concepts to reduce, for example, electrical parasitics, for example, reduction of the contact pad dimensions or planarization with thick dielectric layers, can be applied without negative effects on other VCSEL properties, some other concepts require a search for an appropriate compromise. For example, reducing the mesa diameter reduces not only parasitic capacitances but also decreases the thermal conductivity of the device; performing a deep mesa etch reduces electrical capacitances, but increases the thermal resistance of the laser and so on. Consequently, the overall design was optimized to reach a compromise between small electrical parasitics, good thermal conductivity, low damping, and good manufacturability.

To solve the dilemma of low electrical parasitics and high thermal conductivity, we have applied the two-mesa concept, as a novel feature of our device design. Hereby, the top mesa has a smaller diameter of only $25-36 \mu \mathrm{m}$, which reduces device area and thus the electrical parasitics. The etching of the top mesa is stopped directly after the cavity region to ensure a proper exposure of the aperture layers. The bottom mesa is etched in the following steps and has a larger diameter, increasing the thermal conductivity and thus reducing the self-heating of the device. Consequently, the two-mesa concept allows a combination of low electrical 
parasitics and high thermal conductivity of a laser. In order to reduce electrical parasitic capacitances further, $5-9 \mu \mathrm{m}$ thick layers of photosensitive polymer derived from the B-staged bisbenzocyclobutene (BCB) were employed.

Applying the two-mesa concept high-speed devices with coplanar top contacts in the ground-signal-ground (GSG) configuration and different aperture diameters were fabricated using standard techniques, for example, optical lithography, metal evaporation, dry etching, and so forth. VCSELs with aperture diameters smaller than $3 \mu \mathrm{m}$ have shownsingle mode behavior while lasers with larger aperture diameters were multimode. VCSELs fabricated with the twomesa concept have shown very temperature-stable highspeed behavior in this and also in future experiments, thus we have applied different variations of this concept for all our devices in the next years.

In Figure 2, the scanning electron microscope image of a fabricated VCSEL with the SML-active region is demonstrated [53]. The smaller top mesa with the ring contact and a part of the contact pads in the GSG configuration can be identified on the picture. Also the shape of the larger bottom mesa is clearly seen. All measured VCSELs have shown no noticeable degradation during the measurements, giving indications for good laser reliability.

From all fabricated devices, VCSELs with aperture diameters of 2-3 $\mu \mathrm{m}$ exhibited the best high-temperature behavior and demonstrated open eye operation at $20 \mathrm{Gbit} / \mathrm{s}$ in a wide temperature range from 0 up to $120^{\circ} \mathrm{C}$ with signal-to-noise ratios $(\mathrm{S} / \mathrm{N})$ larger than 5 at all temperatures, as shown in Figure 3 for a VCSEL with the aperture diameter of $3 \mu \mathrm{m}$ [52]. The transmission experiments have been carried out in the back-to-back (BTB) configuration ( $\sim 3 \mathrm{~m}$ of multimode fiber) using a $2^{7}-1$ pseudorandom bit sequence (PRBS) in a nonreturn to zero (NRZ) format. The operation current and the modulation voltage were held constant at all temperatures, making complicated adjustments to the temperature changes and thus, expensive driver electronics redundant. Device with the $3 \mu \mathrm{m}$ aperture diameter demonstrated the output power of $4.6 \mathrm{~mW}$ at room temperature and was still operating even at $150^{\circ} \mathrm{C}$ with the output power of $1.2 \mathrm{~mW}$.

Because of the relative small aperture diameter, the differential resistance of the $3 \mu \mathrm{m}$ aperture VCSEL was about $200 \mathrm{Ohms}$ at room temperature. Coupled to the parasitic capacitances of the aperture and active regions, it resulted in a parasitic cut-off frequency of $\sim 13 \mathrm{GHz}$, limiting the highspeed performance of the laser. To decrease the differential resistance, larger apertures are favorable, but corresponding to (3), the increased mode volume reduces the $D$-factor and thus, the relaxation resonance frequency according to (2). While at lower aperture diameters the relaxation resonance frequency for the presented VCSELs with SML grown active region achieves values larger than $15 \mathrm{GHz}$ at room temperature, increasing the aperture diameter decreases the maximum achievable relaxation resonance frequency to $\sim 12 \mathrm{GHz}$ and below, which becomes smaller than the laser bandwidth of $\sim 13 \mathrm{GHz}$. Additionally, extracted $K$-factors according to (4) have shown limitations of the VCSELs by damping. Thus, further development of the VCSEL structure

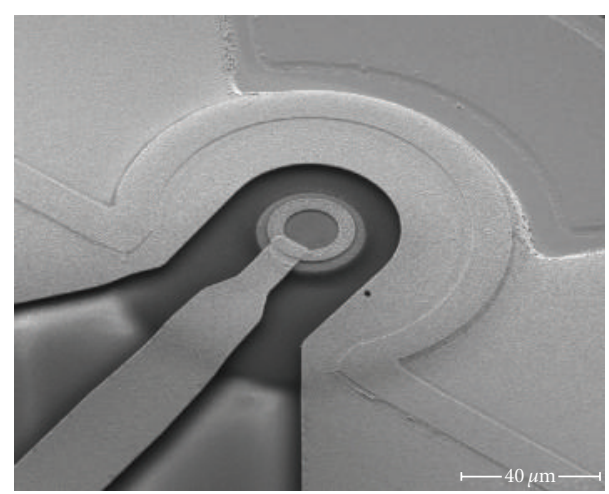

FIgURE 2: A scanning microscope image of a fabricated $980 \mathrm{~nm}$ VCSEL with the active region grown in the submonolayer growth mode. The smaller top mesa with the ring contact and a part of the contact pads in the ground-signal-ground configuration are demonstrated in the picture; also the shape of the larger bottom mesa can be identified.

was needed to achieve larger $D$-factors, relaxation resonance frequencies, and consequently bandwidths.

Based on the previous results described above we have decided to develop the next generation of high-speed hightemperature-stable VCSELs emitting at $980 \mathrm{~nm}$ [54, 60, 61]. To increase the relevance of our research for future commercial applications, we have decided to change the growth platform from $\mathrm{MBE}$ to metalorganic chemical vapor deposition (MOCVD), which is the standard and wellestablished growth technique for large-scale mass production of VCSELs. Since improvements of the active region were also needed to achieve larger $D$-factors, we have additionally decided to develop our VCSELs based on improved conventional quantum wells (QW), since they are routinely applied in commercial VCSELs today and have been proven to have excellent reliability, both GaAs QWs emitting at the standard wavelength of $850 \mathrm{~nm}[26,27]$ as well as InGaAs QWs emitting at longer wavelengths [41, 66, 67]. Consequently in our new VCSEL generation active region consisted of five compressively strained InGaAs QWs each $4.2 \mathrm{~nm}$ thick with $6 \mathrm{~nm}$ thick GaAsP strain compensation layers in between and on both sides of the QW region $[60,61]$. The compressive strain increases the differential gain and consequently the laser bandwidth [83]. The new active region enabled bandwidths of larger than $15 \mathrm{GHz}$ and relaxation resonance frequencies larger than $14 \mathrm{GHz}$ for aperture diameters as large as $7 \mu \mathrm{m}$. Devices with aperture diameters of $10 \mu \mathrm{m}$ demonstrated similar bandwidths. Additional important improvement was the utilization of a double-oxide aperture [36] to decrease parasitic electrical capacitances. Together with the two-mesa design and thick BCB layers, this led to parasitic cut-off frequencies larger than $22 \mathrm{GHz}$ at all temperatures [54, 60, 61].

In Figure 4, optical microscope image of the fabricated VCSEL array together with a zoomed view of a VCSEL with the top mesa diameter of $36 \mu \mathrm{m}$ is demonstrated. Devices with large aperture diameters of $7-10 \mu \mathrm{m}$ exhibited 

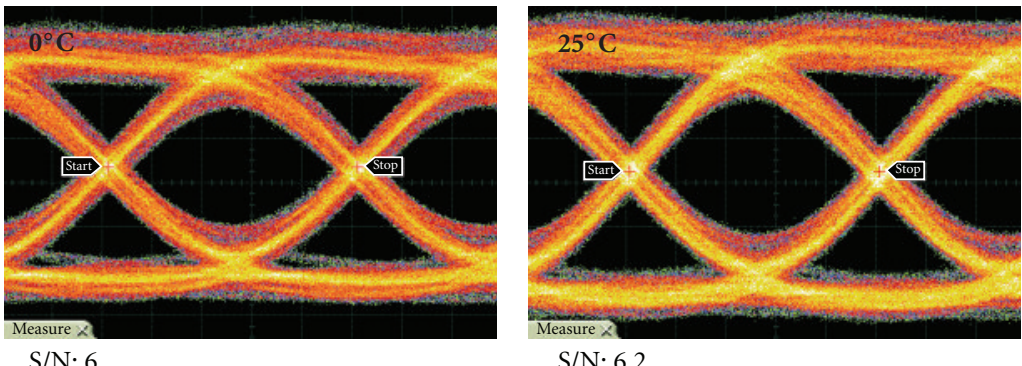

S/N: 6.2
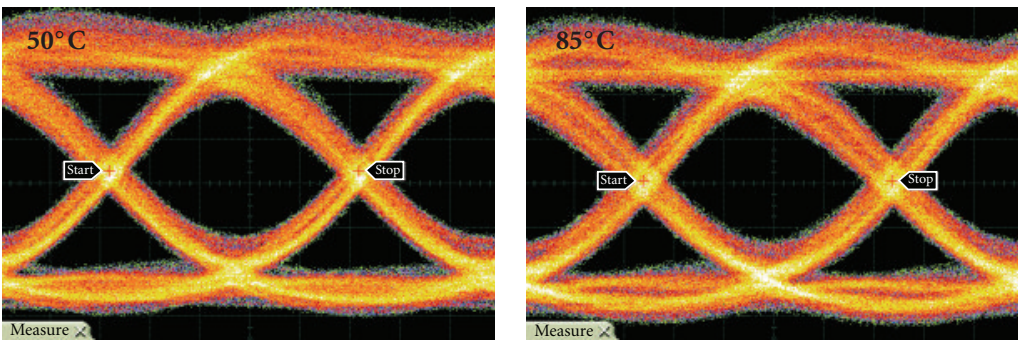

S/N: 6.5

$\mathrm{S} / \mathrm{N}: 6.2$
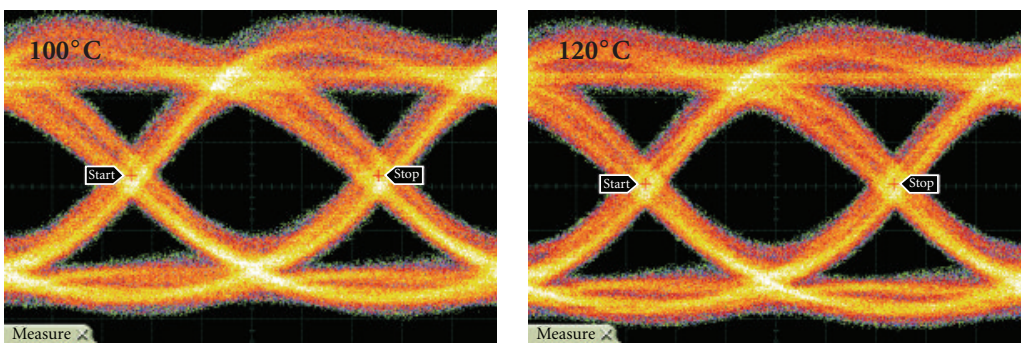

S/N: 5.9

S/N: 5.3

FIgURE 3: Measured optical eye diagrams for a $980 \mathrm{~nm}$ VCSEL with the active region grown in the submonolayer growth mode at the bit rate of $20 \mathrm{Gbit} / \mathrm{s}$ at different temperatures from 0 up to $120^{\circ} \mathrm{C}$ in the BTB, NRZ PRBS $2^{7}-1$ configuration; the oxide aperture diameter of the VCSEL was $3 \mu \mathrm{m}$.

the best performance and demonstrated very-temperaturestable bandwidths around $13-15 \mathrm{GHz}$ in a wide temperature range from room temperature up to $85^{\circ} \mathrm{C}$. These large and very temperature stable bandwidths resulted in the very temperature-stable optical eye diagrams, as shown in Figure 5(a), and led to the demonstration of the worldwide first $980 \mathrm{~nm}$ VCSELs operating error-free at bit rates of up to $25 \mathrm{Gbit} / \mathrm{s}$ at temperatures of up to $85^{\circ} \mathrm{C}$, as shown in Figure 5(b) [60]. All eye diagrams measured with the $10 \mu \mathrm{m}$ aperture VCSEL (Figure 5(a)) are clearly open with S/N larger than 6 at room temperature and larger than 4 at $85^{\circ} \mathrm{C}$. Data transmission with the bit-error rate (BER) smaller than $10^{-12}$ was achieved at both temperatures with the same device without adjustment of the driving parameters during the BER measurements at different temperatures (Figure 5(b)).

To achieve a very temperature-stable bandwidth, it is important to maintain a high relaxation resonance frequency in the whole temperature range, and thus a large and temperature-insensitive $D$-factor, as follows from (2). Since the $D$-factor is strongly dependent on the differential gain, accordingly to (3), it is indispensable to maintain the differential gain as large and as temperature stable as possible. Optimization of the detuning between the cavity resonance wavelength and the wavelength of the gain peak is a natural

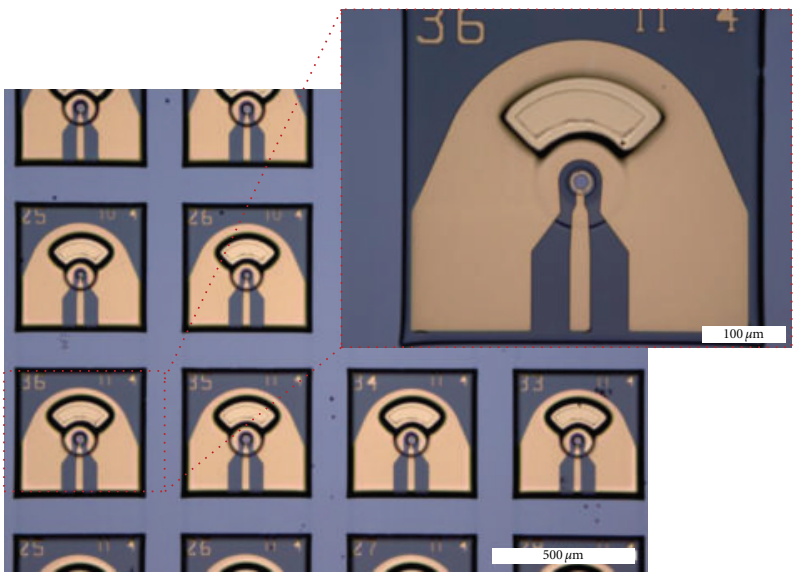

Figure 4: Top-down optical microscope image of the fabricated array of VCSELs with the quantum well active region, including an expanded view of a device with a mesa diameter of $36 \mu \mathrm{m}$.

and elegant tool in a VCSEL to maintain a low threshold current density over a wide temperature range. Since differential gain decreases rapidly with increasing carrier density $[83,84]$, a low and temperature-insensitive threshold carrier 


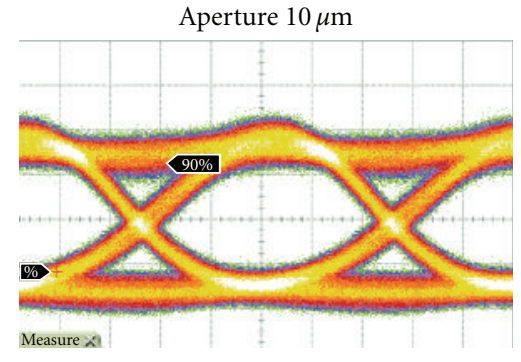

$25^{\circ} \mathrm{C}, 20 \mathrm{Gbit} / \mathrm{s}, 15.2 \mathrm{~mA}, \mathrm{~S} / \mathrm{N}: 8.2$

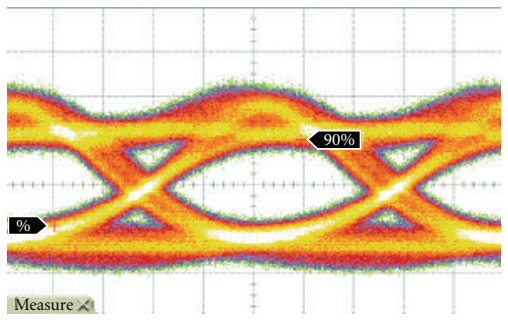

$85^{\circ} \mathrm{C}, 20$ Gbit/s, $14 \mathrm{~mA}, \mathrm{~S} / \mathrm{N}: 5.2$

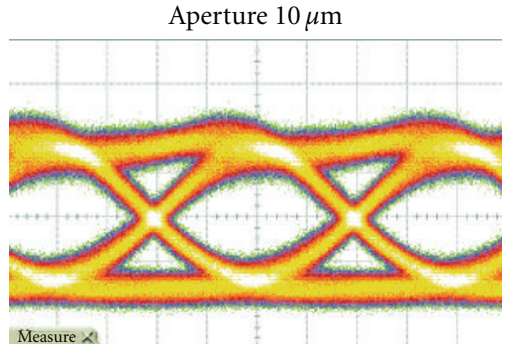

$25^{\circ} \mathrm{C}, 25 \mathrm{Gbit} / \mathrm{s}, 15.3 \mathrm{~mA}, \mathrm{~S} / \mathrm{N}: 6.5$

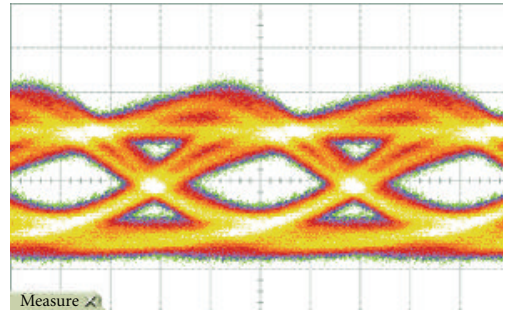

$85^{\circ} \mathrm{C}, 25 \mathrm{Gbit} / \mathrm{s}, 14.5 \mathrm{~mA}, \mathrm{~S} / \mathrm{N}: 4.1$

(a)

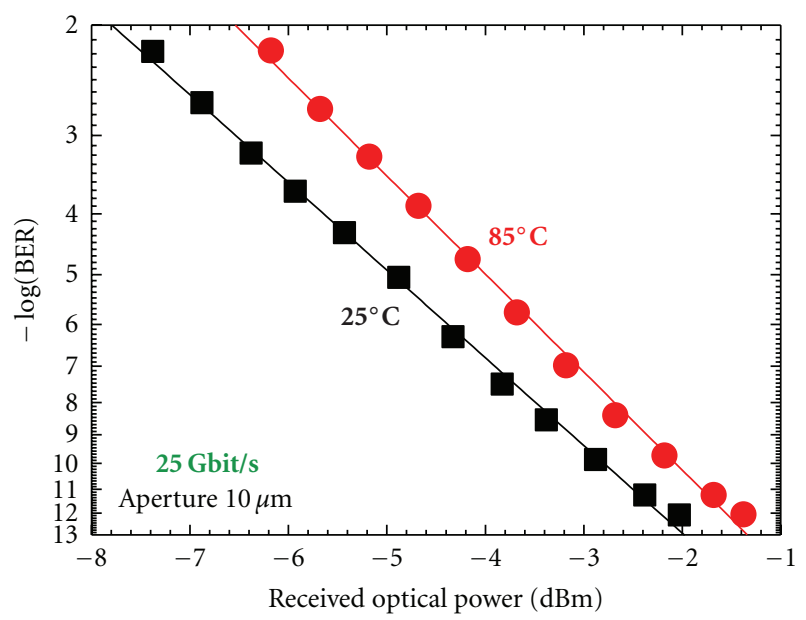

(b)

FIGURE 5: Eye diagrams at 20 and $25 \mathrm{Gbit} / \mathrm{s}$ and temperatures of 25 and $85^{\circ} \mathrm{C}$ with corresponding driving currents and signal to noise ratios in a BTB configuration with $\left(2^{7}-1\right)$ PRBS in a NRZ format (a) and bit error rates at the bit rate of $25 \mathrm{Gbit} / \mathrm{s}$ at 25 and $85^{\circ} \mathrm{C}$ at the current of $12 \mathrm{~mA}$ for a BTB, NRZ, $\left(2^{7}-1\right)$ PRBS configuration (b) for a VCSEL with $10 \mu \mathrm{m}$-diameter oxide aperture.

density helps to maintain the large differential gain and thus high bandwidths at elevated temperatures. In our MOCVD grown VCSELs described above, we have applied a nominally $15 \mathrm{~nm}$ detuning between the cavity resonance wavelength and the wavelength of the photoluminescence (PL) peak of the active region. This optimized detuning resulted in very temperature-stable threshold currents with the variations smaller than $20 \%$ in the whole temperature range from 20 up to $85^{\circ} \mathrm{C}$. The perfect alignment of the cavity-gain detuning manifested itself in the clear minimum of the threshold current as a function of the temperature near $50^{\circ} \mathrm{C}$, just in the middle of the desired temperature interval $[54,60,61]$.

As we can see VCSELs emitting around the wavelength of $980 \mathrm{~nm}$ have made rapid progress just within a couple of years and became able to transfer data at bit rates of up to $25 \mathrm{Gbit} / \mathrm{s}$ in a wide temperature range. Nevertheless, the major and more challenging task to increase the bit rate of the $980 \mathrm{~nm}$ VCSELs at elevated temperatures towards $40 \mathrm{Gbit} / \mathrm{s}$ was still not solved. In the next section, we review the effort and achievements of the worldwide research community in this direction, which ultimately led to realization of $980 \mathrm{~nm}$ VCSELs capable of error-free data transmission at bit rates as high as $44 \mathrm{Gbit} / \mathrm{s}$ at room temperature and $38 \mathrm{Gbit} / \mathrm{s}$ at the elevated temperatures of up to $85^{\circ} \mathrm{C}[62,63]$.

\section{Progress towards $40 \mathrm{~Gb} / \mathrm{S}$ and Beyond}

Already in 2007 researchers from the University of California, Santa Barbara developed advanced $980 \mathrm{~nm}$ bottom-emitting VCSELs which have demonstrated data rates as high as 
$35 \mathrm{Gbit} / \mathrm{s}[46,47]$ at room temperature. To address the limitations of the high-speed laser performance, a number of elegant and effective concepts have been applied in these devices. The doping profiles were optimized to decrease optical losses and at the same time to maintain a large electrical conductivity. A thick oxide aperture with additional deep oxidation layers have been introduced, which together with a thick BCB layer decisively reduces electrical parasitics. It should be noted here that all GaAs-based VCSELs capable of data transmission at bit rates of $35 \mathrm{Gbit} / \mathrm{s}$ and larger utilize special advanced concepts to reduce electrical parasitics inside of the VCSEL mesa, for example, a double aperture and deep oxidation layers at the wavelength of $850 \mathrm{~nm}$ [22], a thick oxide aperture together with deep oxidation layers at the wavelength of $980 \mathrm{~nm}$ [46] or ion implantation at the wavelength of $1100 \mathrm{~nm}$ [41]. Consequently, to increase the bit rate towards $40 \mathrm{Gbit} / \mathrm{s}$, it is indispensable to apply such concepts together with optimization of the contact pad capacitances, for example, via smaller dimensions and thick dielectric layers.

Another important point is the consideration of not only the high-speed performance of the laser, but additionally understanding the significance of all the components built into the complete optical link, especially of the highspeed photodetector. It is remarkable that all successful data transmission experiments at the record high bit rate of $40 \mathrm{Gbit} / \mathrm{s}$ using GaAs-based VCSELs utilized advanced photodetectors developed by industrial partners in special projects, for example, a special designed photodetector with the bandwidth of $30 \mathrm{GHz}$ developed by the company VI Systems for the $850 \mathrm{~nm}$ link [22] or an advanced photoreceiver with integrated transimpedance amplifier (TIA) with the bandwidth of $20 \mathrm{GHz}$ developed by NEC for the $1100 \mathrm{~nm}$ optical data transmission line $[41,45]$. Therefore, we have concentrated our effort on both developing the next generation of our high-speed high-temperature-stable $980 \mathrm{~nm}$ VCSELs as well as searching for industrial partners to get access to advanced photodetectors in this wavelength range.

Based on the scientific results obtained from the previous generations of our $980 \mathrm{~nm}$ VCSELs, especially from the MOCVD grown devices presented at the end of the previous section, which were capable of error-free data transmission at the bit rate of $25 \mathrm{Gbit} / \mathrm{s}$ at temperatures up to $85^{\circ} \mathrm{C}$, we have decided to develop a novel VCSEL structure targeting $40 \mathrm{Gbit} / \mathrm{s}$ data transmission. Therefore, all proven advanced concepts, which have demonstrated strong positive impact on the laser high-speed and high-temperature performance in the previous generations, should be consequently kept in the new VCSEL structure. On the other hand, all discovered limitations should be addressed by the application of new optimization concepts, which ideally should not have negative impact on the already achieved performance. We consistently investigated every of the three limiting factors: electrical parasitics, damping, and thermal processes and in a comprehensive study developed the new VCSEL design for high-speed operation at bit rates in the range of $40 \mathrm{Gbit} / \mathrm{s}$ in a wide temperature range from room temperature up to $85^{\circ} \mathrm{C}$. In the following, we will describe the modifications and achieved results.

As we have already obtained from our previous VCSEL generation grown by MOCVD, electrical parasitic frequencies of larger than $22 \mathrm{GHz}$ were achieved by utilizing a double oxide aperture and thick BCB layers [54, 60, 61]. Together with a small top mesa realized in the two-mesa concept and according to (7), electrical parasitics would not present a strong limitation of our devices, once we keep the double aperture and the thick BCB in the new VCSEL generation. Consequently, these concepts were transferred to our new laser structure without large modifications. Additionally, to decrease electrical resistance and optical losses, doping profiles were optimized further paying respect to dependence of the carrier mobility both on the material as well as on the type of the carriers, for example, electrons or holes. Also optical field distribution was taken into account more carefully, similarly to the procedure described, for example, in [47].

Since damping was one of the major limitations in our previous VCSELs, ultimate concepts for the reduction of the $K$-factor should be applied. The $K$-factor is strongly dependent on the photon lifetime, as shown by (5). Consequently, it is decisive to find concepts which would result in a significant decrease of the photon lifetime without having negative impact on other important laser parameters, for example, differential gain and so forth. As was demonstrated in a very impressive work by the researchers from the Chalmers University of Technology, reduction of the photon lifetime can decrease the damping and thus, increase the laser bandwidth significantly $[39,40]$. In their work, the reflectivity of the top mirror was reduced by dry etching, leading to the reduction of the $K$-factor and thus damping. However, the increase of the mirror losses has negative impact on the threshold current and thus, the differential gain, resulting in decrease of the important $D$-factor and consequently of the maximum relaxation resonance frequency. Thus, to meet the compromise between increased losses and decreased damping, it is important to find a concept which not only decreases the photon lifetime, but simultaneously increases the modal gain, compensating for the increased losses.

An elegant concept for reduction of the photon lifetime without decreasing the differential gain is the application of a shorter VCSEL cavity. The photon lifetime decreases, but at the same time the optical confinement factor increases, compensating for the increase of the optical losses and maintaining the modal gain at a high level $[83,84]$. Additionally, because of the changed balance between the mirror and the internal losses, also the differential efficiency of the laser increases, leading to larger output powers and thus a better S/N $[83,84]$. Since our previous VCSEL structures utilized a $3 \lambda / 2$ long cavity region, the only possibility to shorten the cavity was the introduction of a $\lambda / 2$ long cavity, which is known over many years and has been first investigated in the middle 1990s [87-89]. Consequently we have applied a $\lambda / 2$ cavity concept to our new structures and a comparison between the previous VCSEL design, which demonstrated error-free data transmission at the bit rate of $25 \mathrm{Gbit} / \mathrm{s}$ at temperatures of up to $85^{\circ} \mathrm{C}[54,60,61]$, as described at the 


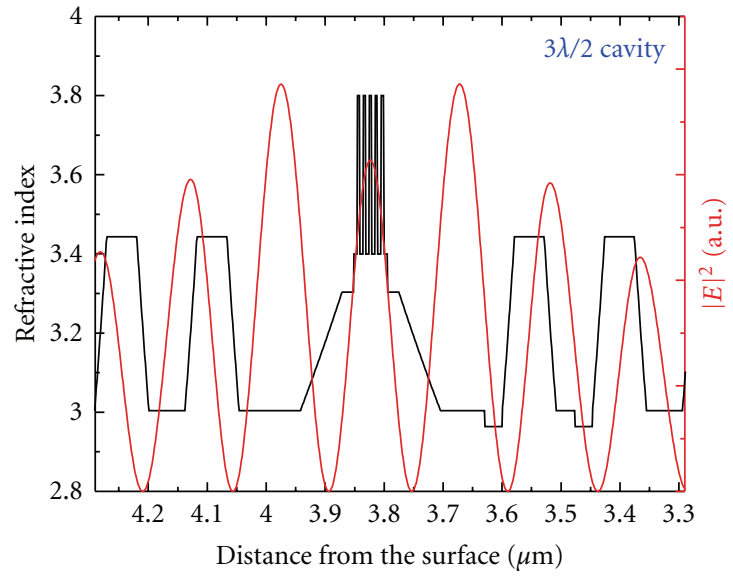

(a)

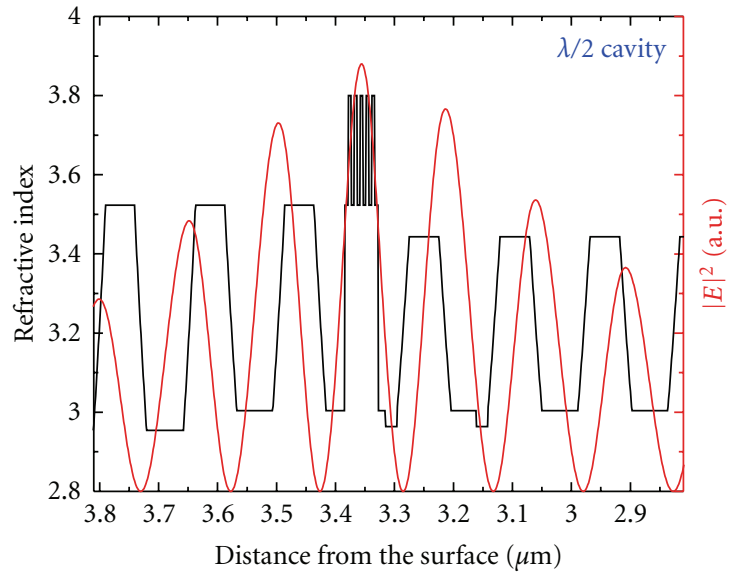

(b)

FIGURE 6: Comparison of the refractive index and simulated optical field intensity distribution inside the previous VCSEL structure with a $3 \lambda / 2$ cavity (a) and inside the new VCSEL structure with a $\lambda / 2$ cavity (b).

end of the previous section and the new VCSEL structure $[62,63]$ is shown in Figure 6. While Figure 6(a) demonstrates the refractive index profile and the simulated optical field intensity distribution in our previous VCSELs with the $3 \lambda / 2$ cavity, Figure 6(b) shows the new VCSEL structure with the $\lambda / 2$ cavity region. The wafer substrate is hereby to the left and the wafer surface to the right. As can be clearly seen, optical field distribution is more advantageous for the shorter cavity, because the middle intensity peak is much stronger as compared to the $3 \lambda / 2$ case. Consequently, the overlap of the lasing mode with active region increases, leading to a strong increase of the optical confinement factor. The calculated value of the optical confinement factor for new VCSELs with the $\lambda / 2$ cavity is $5.1 \%$, which is more than $70 \%$ larger than the value of the confinement factor for VCSELs based on the $3 \lambda / 2$ cavity, which was only $3 \%$. Consequently, the modal gain increases, compensating for increased losses and leaving the carrier density and thus the differential gain hardly affected. Simultaneously the cavity length decreases, leading to decrease of the $K$-factor and damping. In addition to the optimized doping profiles, the $\lambda / 2$ cavity is the second improvement of our previous VCSEL structure. Figure 6 shows also the double aperture in the two pairs of the top DBR directly adjacent to the cavity region both in the previous as well as in the new structure.

After investigations of the electrical parasitics and damping, also concepts to decrease thermal self-heating were studied. Therefore, it is important to increase thermal conductivity of a VCSEL. Introduction of binary materials, for example, binary GaAs and AlAs, instead of ternary AlGaAs alloys especially in the bottom DBR significantly increases the thermal conductivity of the devices. Consequently, we have replaced all layers in the bottom DBR, excepting for the first mirror pair adjacent to the cavity, by binary GaAs and AlAs, as can be also obtained from the refractive index profiles shown in Figure 6(b). Ternary AlGaAs in the first bottom mirror pair was maintained to ensure high yield during the dry etching step for the first mesa in the fabrication process.
Finally, we have carried out a series of experiments with several test structures with different active regions containing InGaAs QWs with different compositions, thicknesses, and quantity. As in our previous VCSELs, active regions with five QWs demonstrated the best performance, but in contrast to the previous devices, new active region contained InGaAs QWs with GaAs barriers, thus, without the GaAsP stress compensation layers. Additionally the thickness of the InGaAs QWs has been increased from $4.2 \mathrm{~nm}$ to $5.0 \mathrm{~nm}$, increasing the optical confinement factor together with the previously described short cavity to the already mentioned value of $5.1 \%$. The number of QWs can be identified also by taking a look onto Figure 6 , where cavity region for both our previous and our new VCSELs are shown. To increase the high temperature stability of the lasers, optimized detuning between the cavity resonance and the PL peak of the active region has been applied, similarly to our previous VCSEL structures.

Summarizing the applied concepts, the new generation of our high-speed high-temperature-stable $980 \mathrm{~nm}$ VCSELs include the following significant design features, both in the epitaxial structure and in the device design:

(i) double oxide aperture,

(ii) small contact pad dimensions and thick BCB layers,

(iii) two-mesa device design with a small top mesa and a larger bottom mesa,

(iv) short $\lambda / 2$ cavity,

(v) binary GaAs/AlAs bottom DBR,

(vi) five compressively strained InGaAs QWs with GaAs barriers,

(vii) optimized doping profiles,

(viii) optimized gain-cavity detuning.

Combined together, the above-described concepts resulted in realization of VCSELs capable of the error-free data transmission at the record high bit rate of $44 \mathrm{Gbit} / \mathrm{s}$ 


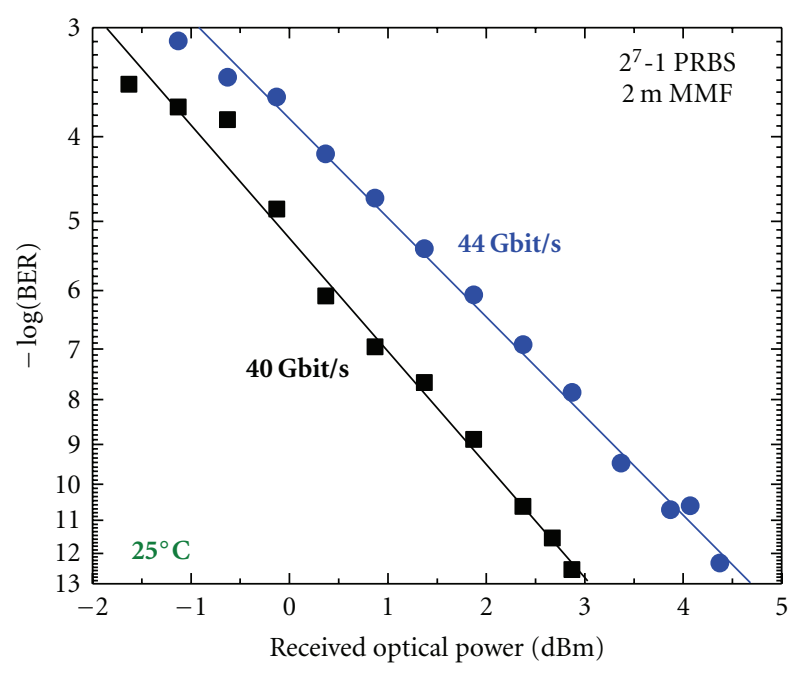

FIGURE 7: Measured bit error rates for the new VCSEL with the $\lambda / 2$ cavity and $6 \mu \mathrm{m}$ aperture in the BTB, NRZ, PRBS $2^{7}-1$ configuration at $25^{\circ} \mathrm{C}$ at the bit rates of 40 and $44 \mathrm{Gbit} / \mathrm{s}$.

at room temperature $[62,63]$, as Figure 7 presents. The experiment was carried out in the BTB configuration $(\sim 2 \mathrm{~m}$ of multimode fiber) using a NRZ, PRBS $2^{7}-1$ digital pattern, and a special advanced photoreceiver with an integrated TIA fabricated by the company $\mathrm{u}^{2} \mathrm{t}$ and exhibiting $\sim 30 \mathrm{GHz}$ bandwidth since the importance of the proper photodetector has been discussed above. For the data transmission experiment, a VCSEL with the oxide aperture diameter of $6 \mu \mathrm{m}$ was measured at the current of $13 \mathrm{~mA}$ and the peak-to-peak modulation voltage of $0.8 \mathrm{~V}$.

With the same device, also data transmission experiments at elevated temperatures up to $120^{\circ} \mathrm{C}$ have been carried out $[62,63]$ in the same configuration using the same photoreceiver from $\mathrm{u}^{2} \mathrm{t}$. Under the same driving conditions, error-free transmission at the elevated temperature of $85^{\circ} \mathrm{C}$ at the record high bit rate of $38 \mathrm{Gbit} / \mathrm{s}$ was demonstrated (Figure 8), which is an improvement of more than $10 \mathrm{Gbit} / \mathrm{s}$ compared to previous VCSEL records at elevated temperatures at any wavelength! Thus, our new generation of $980 \mathrm{~nm}$ lasers is currently the worldwide fastest of any VCSELs at any wavelength both at room as well as at elevated temperatures.

After several years of worldwide effort on the field of high-speed $980 \mathrm{~nm}$ VCSELs, these lasers have finally arrived at the very important milestone: realization of an optical link capable of error-free transmission at the bit rate of $40 \mathrm{Gbit} / \mathrm{s}$. Additionally, bit rates close to $40 \mathrm{Gbit} / \mathrm{s}$ are maintained also at elevated temperatures, making these devices very suitable for parallel optical interconnects especially in future HPC applications.

\section{Conclusions and Outlook}

In the recent years, we have seen impressive progress in the field of high-speed VCSELs emitting around $980 \mathrm{~nm}$. This wavelength has large advantages described in the introduction, which make it very suitable for future shortreach optical interconnects, especially in HPC applications.

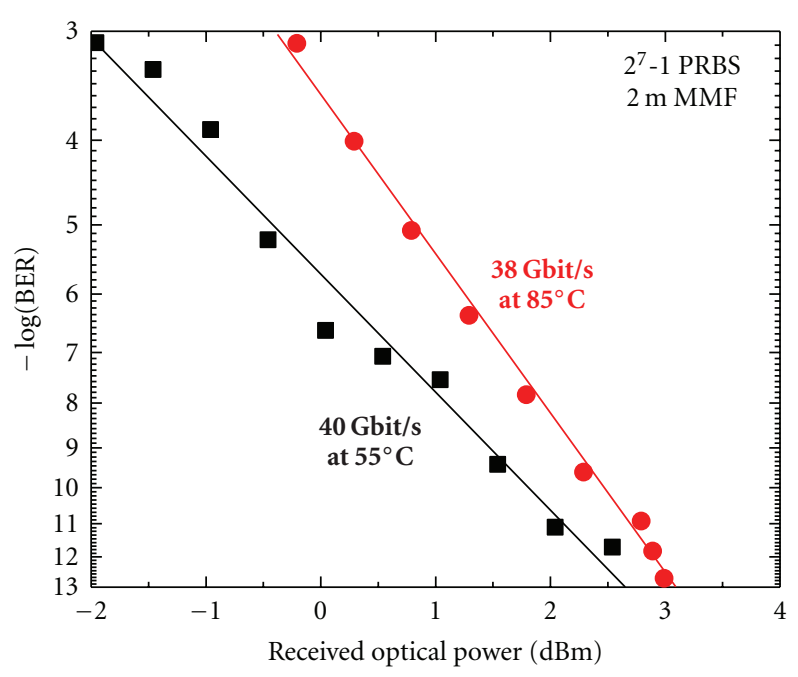

FIGURE 8: Measured bit error rates for the new VCSEL with the $\lambda / 2$ cavity and $6 \mu \mathrm{m}$ aperture in the BTB, NRZ, PRBS $2^{7}-1$ configuration at the bit rate of $40 \mathrm{Gbit} / \mathrm{s}$ at $55^{\circ} \mathrm{C}$ and at the bit rate of $38 \mathrm{Gbit} / \mathrm{s}$ at $85^{\circ} \mathrm{C}$.

The worldwide effort of many excellent researchers from academic institutions as well as industrial companies led to a consequent increase of the data transmission speed of $980 \mathrm{~nm}$ VCSELs first to $25 \mathrm{Gbit} / \mathrm{s}$, then to $35 \mathrm{Gbit} / \mathrm{s}$ and finally to $40 \mathrm{Gbit} / \mathrm{s}$ and now even beyond. Hereby, the increase of the transmission bit rate was achieved not only at one specific temperature, for example, room temperature, but also at elevated temperatures, resulting in VCSELs operating at ultrahigh speed in a wide temperature range, which is especially important for future HPC applications.

The increase of the bit rate was realized by a careful combination of advanced concepts, many of which are wellknown over years and have established themselves as very efficient and at the same time relative straightforward methods. Thus, the overall VCSEL design and fabrication could be maintained relatively inexpensive, making the achieved scientific results more valuable for future commercial applications.

Progress in the field of high-speed VCSELs will definitely continue, leading to further exciting results. In addition to further optimizations of the conventional VCSEL structure novel concepts, for example, VCSELs with photonic crystals [32] or high contrast gratings (HCG) [90, 91], as well as indirectly modulated VCSELs [92-94] and even exciting novel metal-cavity nanolasers based on VCSELlike structures [95-99], are currently intensively investigated and certainly would generate significant knowledge with very high value for both fundamental science as well as application-oriented research.

\section{Acknowledgments}

The authors would like to thank J. A. Lott, N. N. Ledentsov, P. Moser, P. Wolf, F. Hopfer, S. A. Blokhin, A. M. Nadtochiy, A. Payusov, V. A. Shchukin, G. Fiol, K. Pötschke, W. Hofmann, 
V. Haisler, D. Arsenijevic, A. R. Kovsh, S. S. Mikhrin, I. L. Krestnikov, D. A. Livshits, and U. Pohl for significant contributions to this work. This work was supported by the EU FP7 program under agreement no. 224211, the Deutsche Forschungsgemeinschaft (Sfb 787), the State of Berlin $(100 \times$ 100 Optics), and grants of Saint Petersburg Government and Ministry of Education and Science of Russia.

\section{References}

[1] K. Skaugen, "Petascale to exascale: extending Intel's HPC commitment," in Proceedings of the International Supercomputing Conference (ISC '10), Hamburg, Germany, May 2010.

[2] E. Mohammed, A. Alduino, T. Thomas et al., "Optical interconnects system integration for ultra-short-reach applications," Intel Technology Journal, vol. 8, no. 2, pp. 115-128, 2004.

[3] M. J. Kobrinsky, B. A. Block, J. F. Zheng et al., "On-chip optical interconnects," Intel Technology Journal, vol. 8, no. 2, pp. 129142,2004

[4] D. W. Dolfi, "Multi-channel optical interconnects for shortreach applications," in Proceedings of the 53rd Electronic Components and Technology Conference (ECTC'03), pp. 10321039, May 2003.

[5] D. A. B. Miller, "Physical reasons for optical interconnection," International Journal of Optoelectronics, vol. 11, no. 3, pp. 155$168,1997$.

[6] D. G. Kam, M. B. Ritter, T. J. Beukema et al., "Is $25 \mathrm{~Gb} / \mathrm{s}$ on-board signaling viable?" IEEE Transactions on Advanced Packaging, vol. 32, no. 2, pp. 328-344, 2009.

[7] C. Schow, F. Doany, and J. Kash, "Get on the optical bus," IEEE Spectrum, vol. 47, no. 9, Article ID 5557513, pp. 32-56, 2010.

[8] P. Pepeljugoski, M. Ritter, J. A. Kash et al., "Comparison of bandwidth limits for on-card electrical and optical interconnects for $100 \mathrm{~Gb} / \mathrm{s}$ and beyond," in Optoelectronic Integrated Circuits X, vol. 6897, 68970I of Proceedings of SPIE, January 2008.

[9] A. F. Benner, M. Ignatowski, J. A. Kash, D. M. Kuchta, and M. B. Ritter, "Exploitation of optical interconnects in future server architectures," IBM Journal of Research and Development, vol. 49, no. 4-5, pp. 755-775, 2005.

[10] B. J. Offrein, C. Berger, R. Beyeler et al., "Parallel optical interconnects in printed circuit boards," in Optically Based Biological and Chemical Sensing, and Optically Based Materials for Defence, vol. 5990, 59900E of Proceedings of SPIE, Bruges, Belgium, September 2005.

[11] N. Savage, "Linking with light," IEEE Spectrum, vol. 39, no. 8, pp. 32-36, 2002.

[12] H. Soda, K. Iga, C. Kitahara, and Y. Suematsu, "GaInAsP/InP surface emitting injection lasers," Japanese Journal of Applied Physics, vol. 18, no. 12, pp. 2329-2330, 1979.

[13] K. Iga, F. Koyama, and S. Kinoshita, "Surface emitting semiconductor lasers," IEEE Journal of Quantum Electronics, vol. 24, no. 9, pp. 1845-1855, 1988.

[14] K. Iga, "Vertical-cavity surface-emitting laser: its conception and evolution," Japanese Journal of Applied Physics, vol. 47, no. 1, pp. 1-10, 2008.

[15] F. Koyama, "Recent advances of VCSEL photonics," Journal of Lightwave Technology, vol. 24, no. 12, pp. 4502-4513, 2006.

[16] D. Collins, N. Li, D. Kuchta et al., "Development of high-speed VCSELs: $10 \mathrm{~Gb} / \mathrm{s}$ serial links and beyond," in Vertical-Cavity Surface-Emitting Lasers XII, vol. 6908, 690809 of Proceedings of SPIE, San Jose, Calif, USA, January 2008.
[17] F. E. Doany, L. Schares, C. L. Schow et al., "Chip-to-chip optical interconnects," in Proceedings of the Optical Fiber Communication Conference (OFC '06), OFA3, Anaheim, Calif, USA, March 2006.

[18] D. L. Huffaker, D. G. Deppe, K. Kumar, and T. J. Rogers, "Native-oxide defined ring contact for low threshold verticalcavity lasers," Applied Physics Letters, vol. 65, no. 1, pp. 97-99, 1994.

[19] K. D. Choquette, R. P. Schneider, K. L. Lear, and K. M. Geib, "Low threshold voltage vertical-cavity lasers fabricated by selective oxidation," Electronics Letters, vol. 30, no. 24, pp. 2043-2044, 1994.

[20] P. K. Pepeljugoski, J. A. Kash, F. Doany et al., "Low power and high density optical interconnects for future supercomputers," in Proceedings of the Optical Fiber Communication Conference (OFC '10), San Diego, Calif, USA, March 2010, Paper OThX2.

[21] W. Green, S. Assefa, A. Rylyakov, C. Schow, F. Horst, and Y. Vlasov, "CMOS integrated silicon nanophotonics: enabling technology for exascale computational systems," in Proceedings of the SEMICON Japan, Tokyo, Japan, December 2010.

[22] P. Westbergh, J. S. Gustavsson, B. Kögel et al., "40 Gbit/s errorfree operation of oxide-confined $850 \mathrm{~nm}$ VCSEL," Electronics Letters, vol. 46, no. 14, pp. 1014-1016, 2010.

[23] S. A. Blokhin, J. A. Lott, A. Mutig et al., "Oxide-confined $850 \mathrm{~nm}$ VCSELs operating at bit rates up to $40 \mathrm{Gbit} / \mathrm{s}$," Electronics Letters, vol. 45, no. 10, pp. 501-503, 2009.

[24] A. Mutig, S. A. Blokhin, A. M. Nadtochiy et al., "Frequency response of large aperture oxide-confined $850 \mathrm{~nm}$ vertical cavity surface emitting lasers," Applied Physics Letters, vol. 95, no. 13, pp. 131101-1-131101-3, 2009.

[25] A. Mutig, S. Blokhin, A. M. Nadtochiy et al., "High-speed 850 nm oxide-confined VCSELs for DATACOM applications," in Vertical-Cavity Surface-Emitting Lasers XIV, vol. 7615, $76150 \mathrm{~N}$ of Proceedings of SPIE, San Francisco, Calif, USA, January 2010.

[26] J. Wang, C. Ji, D. Soderstrom, T. Jian, and L. Giovane, "850 nm oxide high speed VCSEL development at Avago," in Vertical-Cavity Surface-Emitting Lasers XV, vol. 7952, 795205 of Proceedings of SPIE, San Francisco, Calif, USA, January 2011.

[27] C. Xie, N. Li, C. Lei et al., "New high speed VCSEL product development at Emcore," in Vertical-Cavity Surface-Emitting Lasers XV, vol. 7952, 795206, San Francisco, Calif, USA, January 2011.

[28] C. Ji, J. Wang, D. Söderström, and L. Giovane, " $20 \mathrm{~Gb} / \mathrm{s}$ $850 \mathrm{~nm}$ Oxide VCSEL operating at $25^{\circ} \mathrm{C}-70^{\circ} \mathrm{C}$," IEEE Photonics Technology Letters, vol. 22, no. 10, pp. 670-672, 2010.

[29] R. H. Johnson and D. M. Kuchta, " $30 \mathrm{~Gb} / \mathrm{s}$ directly modulated $850 \mathrm{~nm}$ datacom VCSELs," in Proceedings of the Conference on Lasers and Electro-Optics Postdeadline Session II (CPDB '08), San Jose, Calif, USA, May 2008.

[30] A. N. Al-Omari and K. L. Lear, "VCSELs with a selfaligned contact and copper-plated heatsink," IEEE Photonics Technology Letters, vol. 17, no. 9, pp. 1767-1769, 2005.

[31] A. N. Al-Omari and K. L. Lear, "Polyimide-planarized verticalcavity surface-emitting lasers with $17.0 \mathrm{GHz}$ bandwidth," IEEE Photonics Technology Letters, vol. 16, no. 4, pp. 969-971, 2004.

[32] C. Chen, P. O. Leisher, D. M. Kuchta, and K. D. Choquette, "High-speed modulation of index-guided implantconfined vertical-cavity surface-emitting lasers," IEEE Journal on Selected Topics in Quantum Electronics, vol. 15, no. 3, pp. 673-678, 2009.

[33] J. A. Lott, V. A. Shchukin, N. N. Ledentsov et al., "20 Gbit/s error free transmission with $\sim 850 \mathrm{~nm}$ GaAs-based vertical 
cavity surface emitting lasers (VCSELs) containing InAsGaAs submonolayer quantum dot insertions," in Physics and Simulation of Optoelectronic Devices XVII, vol. 7211, 721114 of Proceedings of SPIE, San Jose, Calif, USA, January 2009.

[34] P. Westbergh, J. S. Gustavsson, A. Haglund et al., "32 Gbit/s transmission experiments using high speed 850 nm VCSELs," in Proceedings of the Conference on Lasers and Electro-Optics and International Quantum Electronics Conference (CLEO/ IQEC '09), Baltimore, Md, USA, May 2009, Paper CMGG6.

[35] P. Westbergh, J. S. Gustavsson, A. Haglund et al., "32 Gbit/s multimode fibre transmission using high-speed, low current density $850 \mathrm{~nm}$ VCSEL," Electronics Letters, vol. 45, no. 7, pp. 366-368, 2009.

[36] P. Westbergh, J. S. Gustavsson, A. Haglund, M. Sköld, A. Joel, and A. Larsson, "High-speed, low-current-density $850 \mathrm{~nm}$ VCSELs," IEEE Journal on Selected Topics in Quantum Electronics, vol. 15, no. 3, pp. 694-703, 2009.

[37] Y. Ou, J. S. Gustavsson, P. Westbergh, A. Haglund, A. Larsson, and A. Joel, "Impedance characteristics and parasitic speed limitations of high-speed $850 \mathrm{~nm}$ VCSELs," IEEE Photonics Technology Letters, vol. 21, no. 24, Article ID 5291742, pp. 1840-1842, 2009.

[38] S. B. Healy, E. P. O'Reilly, J. S. Gustavsson et al., "Active region design for high-speed $850 \mathrm{~nm}$ VCSELs," IEEE Journal of Quantum Electronics, vol. 46, no. 4, pp. 506-512, 2010.

[39] P. Westbergh, J. S. Gustavsson, and B. Kogel, "850 nm VCSEL operating error-free at $40 \mathrm{Gbit} / \mathrm{s}$," in Proceedings of the 22nd IEEE International Semocinductor Laser Conference, Kyoto, Japan, September 2010, Paper WC2.

[40] P. Westbergh, J. S. Gustavsson, B. Kögel, A. Haglund, A. Larsson, and A. Joel, "Speed enhancement of VCSELs by photon lifetime reduction," Electronics Letters, vol. 46, no. 13, pp. 938-940, 2010.

[41] N. Suzuki, T. Anan, H. Hatakeyama et al., "High speed $1.1 \mu \mathrm{m}$-range InGaAs-based VCSELs," IEICE Transactions on Electronics, vol. E92-C, no. 7, pp. 942-950, 2009.

[42] T. Anan, N. Suzuki, K. Yashiki et al., "High-speed InGaAs VCSELs for optical interconnects," in Proceedings of the International Symposium on VCSELs and Integrated Photonics, Tokyo, Japan, December 2007.

[43] H. Hatakeyama, T. Akagawa, K. Fukatsu et al., " 25 Gbit/s $100^{\circ} \mathrm{C}$ operation of highly reliable InGaAs/GaAsP-VCSELs," Electronics Letters, vol. 45, no. 1, pp. 45-46, 2009.

[44] H. Hatakeyama, T. Anan, T. Akagawa et al., "Highly reliable high-speed $1.1 \mu \mathrm{m}$-range VCSELs with InGaAs/GaAsPMQWs," IEEE Journal of Quantum Electronics, vol. 46, no. 6, pp. 890-897, 2010.

[45] K. Fukatsu, K. Shiba, Y. Suzuki et al., " $30 \mathrm{~Gb} / \mathrm{s}$ over $100 \mathrm{~m}$ MMFs Using $1.1 \mu \mathrm{m}$ range VCSELs and photodiodes," IEEE Photonics Technology Letters, vol. 20, no. 11, pp. 909-911, 2008.

[46] Y. C. Chang, C. S. Wang, and L. A. Coldren, "High-efficiency, high-speed VCSELs with 35 Gbit/s error-free operation," Electronics Letters, vol. 43, no. 19, pp. 1022-1023, 2007.

[47] Y. C. Chang and L. A. Coldren, "Efficient, high-data-rate, tapered oxide-aperture vertical-cavity surface-emitting lasers," IEEE Journal on Selected Topics in Quantum Electronics, vol. 15, no. 3, pp. 704-714, 2009.

[48] Y. C. Chang, C. S. Wang, and L. A. Coldren, "Smalldimension power-efficient high-speed vertical-cavity surfaceemitting lasers," Electronics Letters, vol. 43, no. 7, pp. 396-397, 2007.

[49] C. K. Lin, A. Tandon, K. Djordjev, S. W. Corzine, and M. R. T. Tan, "High-speed $985 \mathrm{~nm}$ bottom-emitting VCSEL arrays for chip-to-chip parallel optical interconnects," IEEE Journal on Selected Topics in Quantum Electronics, vol. 13, no. 5, pp. 1332-1339, 2007.

[50] F. Hopfer, A. Mutig, G. Fiol et al., " $20 \mathrm{~Gb} / \mathrm{s} 85^{\circ} \mathrm{C}$ error-free operation of vcsels based on submonolayer deposition of quantum dots," IEEE Journal on Selected Topics in Quantum Electronics, vol. 13, no. 5, pp. 1302-1308, 2007.

[51] F. Hopfer, A. Mutig, M. Kuntz et al., "Single-mode submonolayer quantum-dot vertical-cavity surface-emitting lasers with high modulation bandwidth," Applied Physics Letters, vol. 89, no. 14, Article ID 141106, 2006.

[52] A. Mutig, G. Fiol, P. Moser et al., " $120^{\circ} \mathrm{C} 20$ Gbit/s operation of 980 nm VCSEL," Electronics Letters, vol. 44, no. 22, pp. 13051306, 2008.

[53] A. Mutig, G. Fiol, K. Pötschke et al., “Temperature-dependent small-signal analysis of high-speed high-temperature stable $980 \mathrm{~nm}$ VCSELs," IEEE Journal on Selected Topics in Quantum Electronics, vol. 15, no. 3, Article ID 4783017, pp. 679-686, 2009.

[54] A. Mutig, High Speed VCSELs for Optical Interconnects, Springer Theses, Springer, New York, NY, USA, 2011.

[55] B. E. Lemoff, M. E. Ali, G. Panotopoulos et al., "MAUI: enabling fiber-to-the-processor with parallel multiwavelength optical interconnects," Journal of Lightwave Technology, vol. 22, no. 9, pp. 2043-2054, 2004.

[56] L. Schares, J. A. Kash, F. E. Doany et al., "Terabus: terabit/second-class card-level optical interconnect technologies," IEEE Journal on Selected Topics in Quantum Electronics, vol. 12, no. 5, pp. 1032-1043, 2006.

[57] F. E. Doany, C. L. Schow, C. W. Baks et al., " $160 \mathrm{~Gb} / \mathrm{s}$ bidirectional polymer-waveguide board-level optical interconnects using CMOS-cased transceivers," IEEE Transactions on Advanced Packaging, vol. 32, no. 2, pp. 345-359, 2009.

[58] L. Olejniczak, M. Sciamanna, H. Thienpont et al., "Polarization switching in quantum-dot vertical-cavity surfaceemitting lasers," IEEE Photonics Technology Letters, vol. 21, no. 14, pp. 1008-1010, 2009.

[59] L. Olejniczak, K. Panajotov, H. Thienpont et al., "Polarization swithing and polarization mode hopping in quantum dot vertical-cavity surface-emitting lasers," Optics Express, vol. 19, no. 3, pp. 2476-2484, 2011.

[60] A. Mutig, J. A. Lott, S. A. Blokhin et al., "Highly temperaturestable modulation characteristics of multioxide-aperture high-speed $980 \mathrm{~nm}$ vertical cavity surface emitting lasers," Applied Physics Letters, vol. 97, no. 15, Article ID 151101, 2010.

[61] A. Mutig, J. A. Lott, and S. A. Blokhin, "High-speed highly temperature stable $980 \mathrm{~nm}$ VCSELs operating at $25 \mathrm{~Gb} / \mathrm{s}$ at up to $85^{\circ} \mathrm{C}$ for short reach optical interconnects," in VerticalCavity Surface-Emitting Lasers XV, vol. 7952, 79520H of Proceedings of SPIE, San Francisco, Calif, USA, January 2011.

[62] W. Hofmann, P. Moser, P. Wolf, A. Mutig, M. Kroh, and D. Bimberg, " $44 \mathrm{~Gb} / \mathrm{s}$ VCSEL for optical interconnects," in Proceedings of the Optical Fiber Communication Conference and Exhibition and the National Fiber Optic Engeneers Conference (OFC/NFOEC), Los Angeles, Calif, USA, March 2011, Paper PDPC5.

[63] A. Mutig, "High speed 850 and $980 \mathrm{~nm}$ VCSELs," in Proceedings of the OIDA's Short-Distance, High-Density Optical Interconnects Workshop, Stanford, Calif, USA, April 2011.

[64] A. N. Al-Omari, G. P. Carey, S. Hallstein, J. P. Watson, G. Dang, and K. L. Lear, "Low thermal resistance high-speed topemitting 980 nm VCSELs," IEEE Photonics Technology Letters, vol. 18, no. 11, pp. 1225-1227, 2006.

[65] R. Safaisini, J. R. Joseph, D. Louderback, X. Jin, A. N. AlOmari, and K. L. Lear, "Temperature dependence of $980 \mathrm{~nm}$ 
oxide-confined VCSEL dynamics," IEEE Photonics Technology Letters, vol. 20, no. 14, pp. 1273-1275, 2008.

[66] K. Takaki, S. Imai, S. Kamiya et al., "1060 nm VCSEL for interchip optical interconnections," in Vertical-Cavity SurfaceEmitting Lasers XV, vol. 7952, 795204 of Proceedings of SPIE, San Francisco, Calif, USA, January 2011.

[67] K. Takaki, N. Iwai, S. Kamiya et al., "Experimental demonstration of low jitter performance and high reliable $1060 \mathrm{~nm}$ VCSEL arrays for $10 \mathrm{Gbpsx} 12 \mathrm{ch}$ optical interconnection," in Vertical-Cavity Surface-Emitting Lasers XIV, vol. 7615, 761502 of Proceedings of SPIE, San Francisco, Calif, USA, January 2010.

[68] F. Hopfer, I. Kaiander, A. Lochmann et al., "Vertical-cavity surface-emitting quantum-dot laser with low threshold current grown by metal-organic vapor phase epitaxy," Applied Physics Letters, vol. 89, no. 6, Article ID 061105, 2006.

[69] R. Safaisini, J. R. Joseph, and K. L. Lear, "Scalable high-CWpower high-speed $980 \mathrm{~nm}$ VCSEL arrays," IEEE Journal of Quantum Electronics, vol. 46, no. 11, Article ID 5556436, pp. 1590-1596, 2010.

[70] R. Safaisini, J. R. Joseph, G. Dang, and K. L. Lear, "Scalable high-power, high-speed CW VCSEL arrays," Electronics Letters, vol. 45, no. 8, pp. 414-415, 2009.

[71] A. N. Al-Omari, K. L. Lear, and H. Hamad, "High-speed $980 \mathrm{~nm}$ VCSELs with integrated distributed losses for mode control," in Vertical-Cavity Surface-Emitting Lasers XIV, vol. 7615, 76150P of Proceedings of SPIE, San Francisco, Calif, USA, January 2010.

[72] E. Soderberg, J. S. Gustavsson, P. Modh et al., "Hightemperature dynamics, high-speed modulation, and transmission experiments using $1.3 \mu \mathrm{m}$ InGaAs single-mode VCSELs," Journal of Lightwave Technology, vol. 25, no. 9, pp. 2791-2798, 2007.

[73] E. Söderberg, P. Modh, J. S. Gustavsson et al., "High speed, high temperature operation of $1.28 \mu \mathrm{m}$ singlemode InGaAs VCSELs," Electronics Letters, vol. 42, no. 17, pp. 978-979, 2006.

[74] R. L. Naone, A. W. Jackson, S. A. Feld, D. Galt, K. J. Malone, and J. J. Hindi, "Monolithic GaAs-based $1.3 \mu \mathrm{m}$ VCSEL directly-modulated at $10 \mathrm{~Gb} / \mathrm{s}$," in Proceedings of the Conference on Lasers and Electro-Optics (CLEO'01), Baltimore, Md, USA, May 2001, Paper CPD13.

[75] M. Laemmlin, G. Fiol, M. Kuntz et al., "Quantum dot based photonic devices at $1.3 \mu \mathrm{m}$ : direct modulation, mode-locking, SOAs and VCSELs," Physica Status Solidi C, vol. 3, no. 3, pp. 391-394, 2006.

[76] N. N. Ledentsov, J. A. Lott, V. A. Shchukin et al., "Quantum dot insertions in VCSELs from 840 to $1300 \mathrm{~nm}$ : growth, characterization, and device performance," in Quantum Dots, Particles, and Nanoclusters VI, vol. 7224, 72240P of Proceedings of SPIE, San Jose, Calif, USA, January 2009.

[77] H. Shimizu, C. Setiagung, M. Ariga et al., " $1.3 \mu \mathrm{m}$-range GaInNAsSb-GaAs VCSELs," IEEE Journal on Selected Topics in Quantum Electronics, vol. 9, no. 5, pp. 1214-1219, 2003.

[78] F. Koyama, "Wavelength engineering of surface emitting lasers for high capacity short reach systems," in Active and Passive Optical Components for WDM Communications III, vol. 5246, 1 of Proceedings of SPIE, Orlando, Fla, USA, September 2003.

[79] A. W. Jackson, R. L. Naone, L. Chirovsky et al., "1.3 micron InGaAsN VCSELs for telecom and datacom applications," in Semiconductor Lasers for Lightwave Communication Systems, vol. 4533 of Proceedings of SPIE, Denver, CO, USA, August 2001.

[80] D. A. Louderback, M. A. Fish, J. F. Klem et al., "Development of bottom-emitting $1300 \mathrm{~nm}$ vertical-cavity surface-emitting lasers," IEEE Photonics Technology Letters, vol. 16, no. 4, pp. 963-965, 2004.

[81] D. W. Kisker, L. M. F. Chirovsky, R. L. Naone et al., " $1.3 \mu \mathrm{m}$ VCSEL production issues," in Vertical-Cavity Surface-Emitting lasers VIII, vol. 5364 of Proceedings of SPIE, San Jose, Calif, USA, January 2004.

[82] H. Riechert, A. Ramakrishnan, and G. Steinle, "Development of InGaAsN based $1.3 \mu \mathrm{m}$ VCSELs," Semiconductor Science and Technology, vol. 17, no. 8, pp. 892-897, 2002.

[83] L. A. Coldren and S. W. Corzine, Diode Lasers and Photonic Integrated Circuits, Wiley, New York, NY, USA, 1995.

[84] S. L. Chuang, Physics of Photonic Devices, Wiley, Hoboken, NJ, USA, 2009.

[85] Y. Satuby and M. Orenstein, "Mode-coupling effects on the small-signal modulation of multitransverse-mode verticalcavity semiconductor lasers," IEEE Journal of Quantum Electronics, vol. 35, no. 6, pp. 944-954, 1999.

[86] L. G. Zei, S. Ebers, J. R. Kropp, and K. Petermann, "Noise performance of multimode VCSELs," Journal of Lightwave Technology, vol. 19, no. 6, pp. 884-892, 2001.

[87] D. L. Huffaker, J. Shin, and D. G. Deppe, "Low threshold halfwave vertical-cavity lasers," Electronics Letters, vol. 30, no. 23, pp. 1946-1947, 1994.

[88] D. L. Huffaker and D. G. Deppe, "Half-wave cavity verticalcavity surface-emitting lasers with native oxide/GaAs lower distributed Bragg reflectors," in Vertical-Cavity SurfaceEmitting Lasers, vol. 3003, 154 of Proceedings of SPIE, February 1997.

[89] L. A. Graham, D. L. Huffaker, T. H. Oh, and D. G. Deppe, "Effects of steam oxidation on a single $\mathrm{In}_{0.20} \mathrm{Ga}_{0.80}$ As quantum well in a half-wave microcavity VCSEL," in Vertical-Cavity Surface-Emitting Lasers, vol. 3003, 63 of Proceedings of SPIE, San Jose, Calif, USA, February 1997.

[90] M. C. Y. Huang, Y. Zhou, and C. J. Chang-Hasnain, "Single mode high-contrast subwavelength grating vertical cavity surface emitting lasers," Applied Physics Letters, vol. 92, no. 17, Article ID 171108, 2008.

[91] Y. Rao, C. Chase, and C. J. Chang-Hasnain, "Multiwavelength HCG-VCSEL array," in Proceedings of the 22nd IEEE International Semocinductor Laser Conference, Kyoto, Japan, September 2010, Paper MB5.

[92] N. N. Ledentsov, J. A. Lott, V. A. Shchukin et al., "Optical components for very short reach applications at $40 \mathrm{~Gb} / \mathrm{s}$ and beyond," in Physics and Simulation of Optoelectronic Devices XVIII, vol. 7597, 75971F of Proceedings of SPIE, San Francisco, Calif, USA, January 2010.

[93] F. Hopfer, A. Mutig, A. Strittmatter et al., "High-speed directly and indirectly modulated VCSELs," in Proceedings of the 20th International Conference on Indium Phosphide and Related Materials (IPRM '08), Versailles, France, May 2008.

[94] T. D. Germann, A. Strittmatter, A. Mutig et al., "Monolithic electro-optically modulated vertical cavity surface emitting laser with $10 \mathrm{~Gb} / \mathrm{s}$ open-eye operation," Physica Status Solidi C, vol. 7, no. 10, pp. 2552-2554, 2010.

[95] C. Y. Lu, S. W. Chang, S. L. Chuang, T. D. Germann, and D. Bimberg, "Metal-cavity surface-emitting microlaser at room temperature," Applied Physics Letters, vol. 96, no. 25, Article ID 251101, 2010.

[96] C.-Y. Lu, S.-W. Chang, S. L. Chuang, T. D. Germann, U. W. Pohl, and D. Bimberg, "CW substrate-free metal-cavity surface microemitters at $300 \mathrm{~K}$," Semiconductor Science and Technology, vol. 26, no. 1, pp. 014012-1-014012-7, 2010.

[97] C.-Y. Lu, S.-W. Chang, S. L. Chuang, T. D. Germann, U. W. Pohl, and D. Bimberg, "Characteristics of metal-cavity 
surface-emitting microlaser," in Proceedings of the 23rd Annual Meeting IEEE Photonics Society, pp. 240-241, Denver, Colo, USA, November 2010, IEEE Catalog: CFP10LEO_CDR.

[98] C.-Y. Lu, S.-W. Chang, S. L. Chuang, T. D. Germann, and D. Bimberg, "Substrate-free metal cavity surface-emitting laser with CW operation at room temperature," in Proceedings of the International Semiconductor Laser Conference (ISLC '10), pp. 15-16, Kyoto, Japan, September 2010.

[99] C. Lu, S. L. Chuang, T. D. Germann, A. Mutig, and D. Bimberg, "Novel metal-cavity nanolasers at room temperature," in Proceedings of the Conference on Lasers and Electro-Optics (CLEO), Baltimore, Md, USA, May 2011, Paper JMA4. 

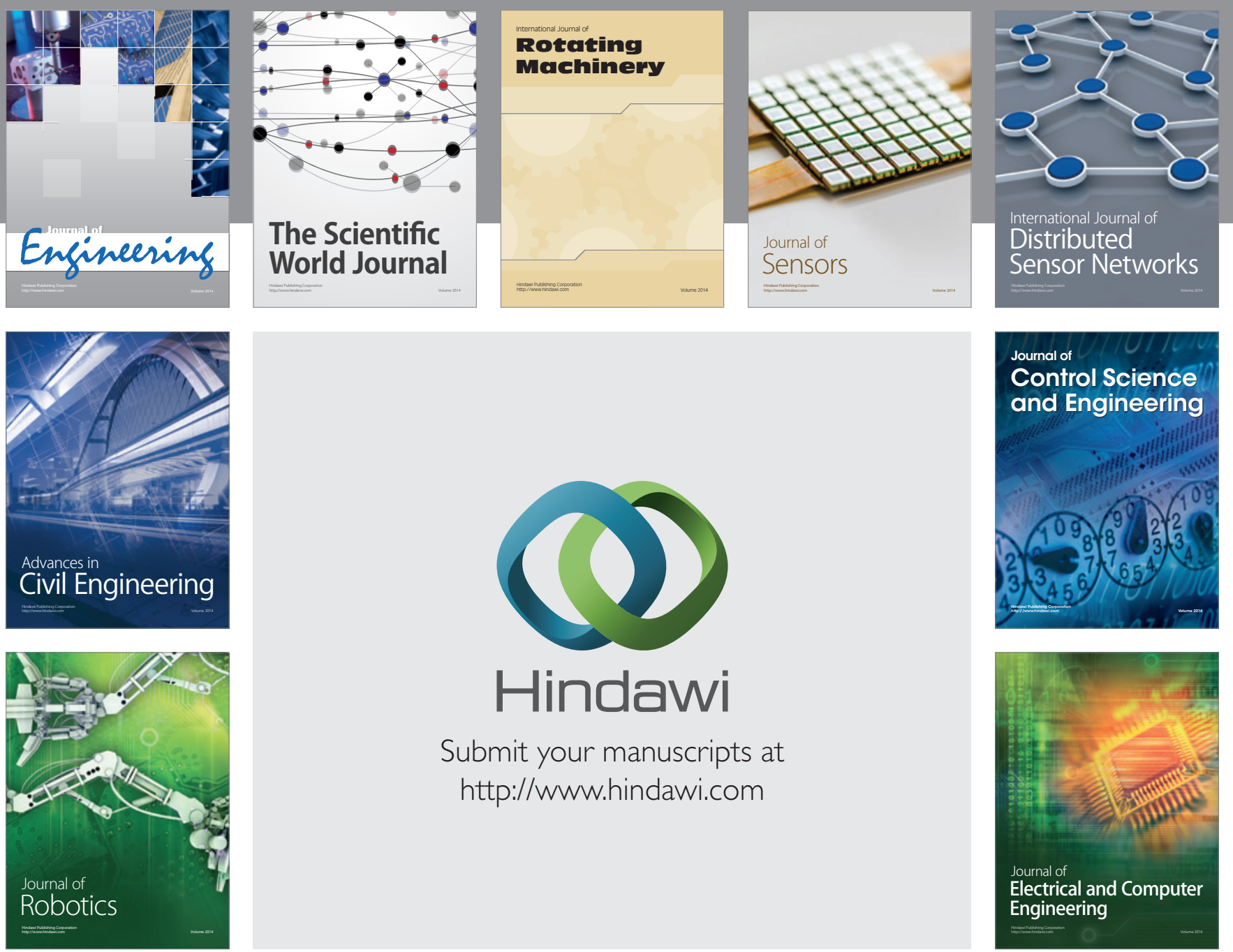

Submit your manuscripts at

http://www.hindawi.com
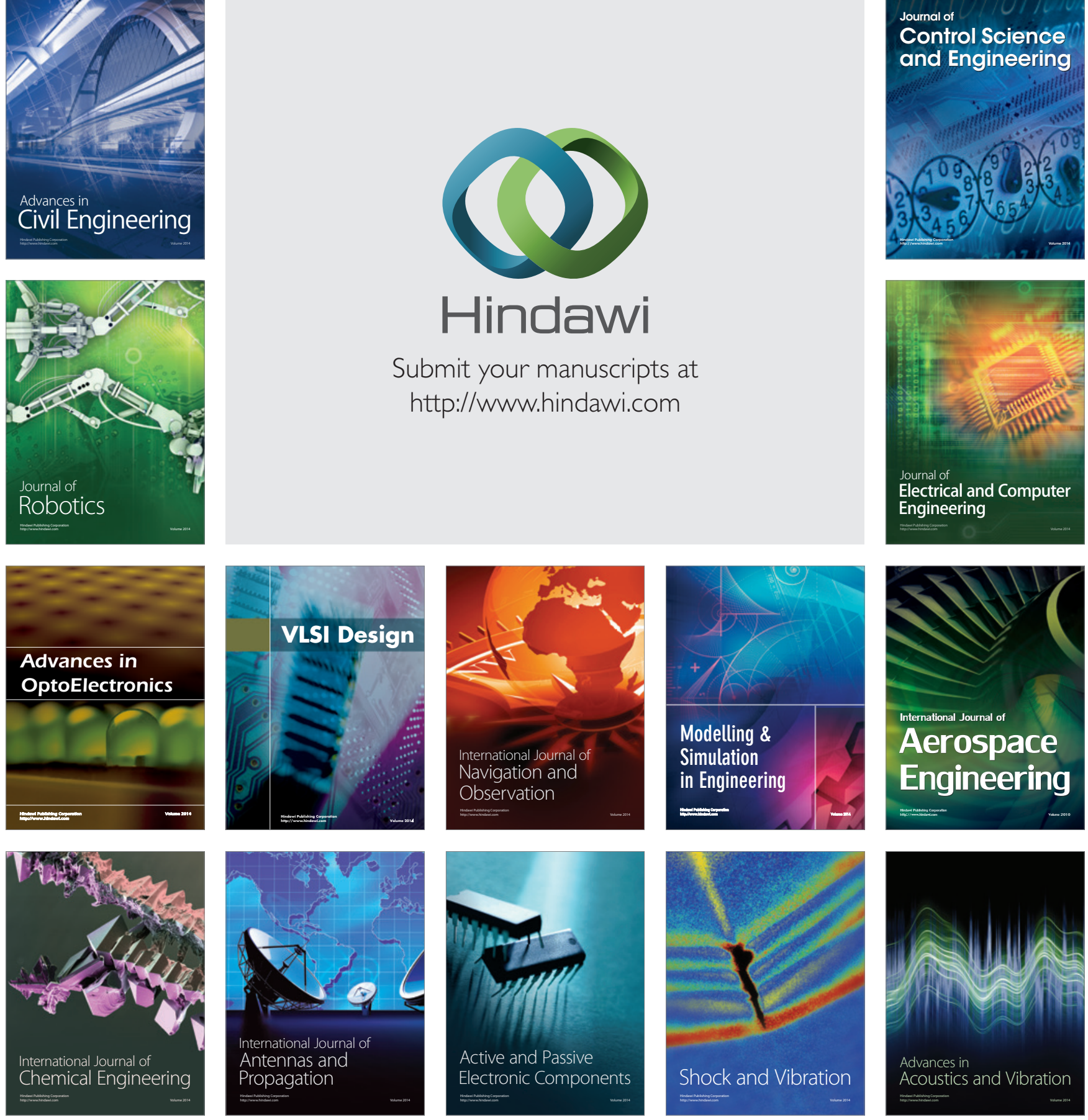